\title{
Antimetabolite FF-10502
}

National Cancer Institute

\section{Source}

National Cancer Institute. Antimetabolite FF-10502. NCI Thesaurus. Code C125690.

An antimetabolite with potential antineoplastic activity. Upon administration, FF-10502 is

able to enter the nucleus where it inhibits DNA polymerases, thereby preventing DNA

synthesis and halting tumor cell proliferation. 